\title{
DEVELOPMENT AND CHARACTERIZATION OF PRECIROL ATO 88 BASE IN NANOSTRUCTURED LIPID CARRIERS (NLC) FORMULATION WITH THE PROBE SONICATION METHOD
}

\author{
GARNADI JAFAR ${ }^{1,2}$, MARLINE ABDASSAH ${ }^{1}$, TAOFIK RUSDIANA ${ }^{1}{ }^{*}$, RIZKI KHAIRUNISA ${ }^{2}$
}

${ }^{1}$ Department of Pharmaceutics and Pharmaceutical Technology, Padjadjaran University, Indonesia, ${ }^{2}$ Department of Pharmaceutics and Pharmaceutical Technology, Bhakti Kencana University Bandung, Indonesia

*Email: t.rusdiana@unpad.ac.id

Received: 16 Sep 2020, Revised and Accepted: 10 Oct 2020

\section{ABSTRACT}

Objective: Adapalene is a medicinal ingredient that can be used to treat acne. Adapalene has a Log P value of 8.6 and has high lipophilic and low solubility in water and is potentially degraded. Adapalene NLC can increase biphasic drug penetration at low doses but has good reactivity and provides occlusive properties that can increase skin hydration, thereby accelerating acne treatment.

Methods: Forming Adapalene NLC using the method of heat homogenization followed by ultrasonication probe. The NLC formulas used were Precirol ATO5 ${ }^{\circledR} 4.0 \%$, Myritol ${ }^{\circledR} 2 \%$, Cremophor RH 40 1\%, Plantacare $1 \%$, Tegocare $1 \%$, and Adapalene $0.3 \%$. Following that is the characterization of particle size, polydispersity index, zeta potential, efficiency entrapment.

Results: The results showed the measurement of particle size with a range (150-318 nm), index polydispersion showed (0.12-0.36) and zeta potential (-26)-(-60 mV) and efficient entrapment testing showed results (84-98\%). In the TEM morphological evaluation of images showing spherical and evenly distributed forms, this is in line with the results of the adapalene NLC characterization.

Conclusion: These results suggest that NLC containing adapalene showed excellent result.

Keywords: Adapalene, Precirol ATO5 $®$, Nanostructured Lipid Carriers (NLC), Probe Sonication

(C) 2021 The Authors. Published by Innovare Academic Sciences Pvt Ltd. Thisis an open access article under theCC BYlicense (https://creativecommons.org/licenses/by/4.0/) DOI: https://dx.doi.org/10.22159/ijap.2021.v13s3.08 Journal homepage: https://innovareacademics.in/journals/index.php/ijap

\section{INTRODUCTION}

Nanostructured lipid carrier (NLC) is one of the drug delivery systems with modifications that is able to improve the physicochemical properties of an active ingredient [1]. Carrier lipid nanostructured is a second-generation nanocarrier as the first generation improvement, namely solid lipid carrier (SLN) [2]. SLN only consists of solid lipids without liquid lipids; this is a weakness of SLN because the matrix structure owned by SLN is very solid, resulting in low loading capacity and the possibility of the expulsion of the drug during storage and this system also has a high potential for explosive eruptions drug [3]. The liquid lipid component in NLC functions to overcome SLN weaknesses, namely to disrupt the conformation of the solid lipid matrix so that it does not become a perfect matrix of solid lipid crystals during storage and also the absorption of active substances increases [4,5]. Adapalene (ADA) is a new synthetic retinoid ( $3^{\text {rd }}$ generation) as an anti-inflammatory, has a high affinity for the retinoic acid (RAR) $\beta$ and RAR $\gamma$ receptors, and is effective in the treatment of mild to moderate acne in humans [6]. In USA, Adapalene in gel form is used for the topical treatment of moderate to severe acne vulgaris with a concentration of $0.1 \%$ and $0.3 \%$, but the effectiveness of which is superior to that gel ADA $0.3 \%$ [7]. Adapalene has low solubility in water or is lipophilic and has a high melting point of more than $300{ }^{\circ} \mathrm{C}[8]$. High ADA melting points can be associated with side effects that can make redness on the skin when in direct contact with the epidermal layer. Nanostructured carious lipids can be used to protect pharmaceutical active ingredients, namely adapalene which has lipophilic physicochemical properties and crystalline form that can irritate when in direct contact with the skin but have great benefits, especially as anti-acne [9]. NLC can increase targeted drug delivery, especially by topical administration route; the purpose of acne treatment is the dermis layer, so the NLC system is appropriate [10].

\section{MATERIALS AND METHODS}

\section{Study materials}

The ingredients used consist of active ingredients namely Adapalen (PT. Olon spa), Glyceryl Palmitostarate (Precirol ${ }^{\circledR} \quad$ ATO5) solid lipids from PT. Gattefose, liquid lipid Caprylic Triglyceride (Myritol®
318), surfactant PEG-40-Hydrogenated Castor Oil (Cremophore RH $40 ®$ ), surfactant Lauryl Triglyceride (Plantacare $®$ ), and Poliglyceryl-3 Methil Distearate Glucose (Tegocare $($ ) from Evonic Industries AG, Methanol Pro Analysis (Merck).

\section{FTIR testing}

FT-IR test is intended to determine the compatibility between the materials used $[11,12]$. This test is carried out by analyzing the active substance Adapalen, Precirol ${ }^{\circledR}$ AT05 solid lipid, and a mixture of Precirol ${ }^{\circledR}$ AT05-Adapalen solid lipid. The sample is crushed and placed in the sample container until it meets the crystal part of the Agilent Cary 630 FT-IR spectrophotometer instrument then the sample spectrum results are compared [13].

\section{X-Ray diffractometry (X-RD) testing}

Analysis of the active substance Adapalene, Precirol ${ }^{\circledR}$ AT05 solid lipids, and a mixture of Tretinoin-solid lipids using the X-RD Bruker D8 instrument to determine the crystallinity of the ingredients used $[14,15]$. Samples were analyzed with a scanning speed of $1 \% \mathrm{~min}$

\section{Differential scanning calorimetry test (DSC)}

The DSC test was carried out to determine the melting point and properties of the material, adapalene, Precirol ${ }^{\circledR}$ ATO5 solid lipid, and a solid-Adapalene lipid mixture placed in an aluminum plate on the DSC instrument Thermal Analysis License (USA), then heated from $20-400{ }^{\circ} \mathrm{C}$ at speed heating $10^{\circ} \mathrm{C} / \mathrm{min}$. The data obtained in the form of thermograms with thermal parameters such as onset, offset, and maximum peak.

\section{Preparation of NLCS}

NLC was made using the hot homogenization method followed by probe sonication [16]. As much as $0.1 \%$ of adapalene is put into Precirol ${ }^{\circledR}$ ATO5 and liquid lipids (Caprylic Triglyceride (Myritol® 318) then melted (Phase A). Campervan surfactant with a water phase using magnetic-stirrer (IKA® C-Mag H54) (Phase B). Phase B is added to phase $\mathrm{A}$, then stirred using a high-shear homogenizer (Ultra Thurrax IKA® T25) to form pre-emulsions [17-19]. The next 
step is to reduce particle size using a sonicator probe (Ivymen Ultrasonic Homogenizers CY-500) [20].

\section{Physicochemical characterization of particles}

Adapalene NLC formulations were characterized, consisting of particle size, index polydispersion, and zeta potential using Malvern ZSP (England) zeta sizer particle size gauges at room temperature $\left(25{ }^{\circ} \mathrm{C}\right)$ [21]. Adapter NLC samples were taken 5 drops and then added with water up to $10 \mathrm{ml}$ and put into a disposable cuvette[22]. To confirmed the formation of NLC adapalene, do to characterization Test X-Ray diffractometry (X-RD Bruker D8) and Differential Scanning Calorimetry testing is perform to recognize changes that occur in NLC formulated with adapalene after probe sonication methods [23].

The morphological formula of NLC adapalene was formed using transmission electron microscopy (TEM Jeol Japan JEM 1400. A total of $1 \mathrm{~g}$ of the adapalene NLC oil phase is dispersed in $5 \mathrm{ml}$ of deionized water before analysis. The mixture is then stirred and dropped $10 \mu \mathrm{l}$ on the specimen. A lat grid of 400 mesh then dropped $10 \mathrm{ml}$ of uranyl acetate over the grid and the rest of the droplets is cleaned again using filter paper, allowed to stand for $30 \mathrm{~min}$ to dry, and put into a TEM tool to capture [24].

\section{Entrapment efficiency (EE)}

The adsorption efficiency calculation is performed by $1 \mathrm{ml}$ Adapalene NLC inserted in Vivaspin filter tubes (Vivaspin, Goettingen, Germany) with a membrane filter that has a $5 \mathrm{kDa}$ molecular weight cut-off and centrifuged at $14,500 \mathrm{rpm}$ for $3 \mathrm{~h}$. Then the supernatant is taken and diluted, then measured by the UV
Spectrophotometry method (Shimadzu 1800) at the maximum wavelength to obtain levels of Adapalene that is not absorbed (unentrapped). Then the entrapment efficiency (EE) can be calculated using the following equation [25]:

$$
\% \mathrm{EE}=\frac{\text { Total adapalene }- \text { free adapalene }}{\text { Total adapalene }} \times 100
$$

\section{RESULTS AND DISCUSSION}

\section{Evaluation and characterization of adapalene NLC}

FT-IR test is a means of qualitative identification by involving the infrared ray spectrum, which provides information on the presence or absence of interactions on the mixture of materials used in the NLC formula [28]. This test consisted of a single adapalene analysis, a single Precirol ${ }^{\circledR}$ AT05 solid lipid and a mixture of both. The fig. above shows that a single Adapalene has sharp peaks at frequencies of $2914.73 \mathrm{~cm}-1$ and $2849.74 \mathrm{~cm}-1$, while Precirol ${ }^{\circledR}$ ATO5 sharp peaks are at frequencies $2912.54 \mathrm{~cm}-1$ and $2848.30 \mathrm{~cm}-1$. This proves that both have similar characteristics in terms of the type of bond even though they have different frequencies; this difference is caused by the difference in vibration between the two. Similar to the Precirol ${ }^{\circledR}$ AT05 spectrum, the mixture spectrum of Adapalene and Precirol ${ }^{\circledR}$ AT05 has sharp peaks at $2912.54 \mathrm{~cm}-1$ and $2848.30 \mathrm{~cm}-1$ without the formation of new peaks, this revealed that Adapalene was not detected as a whole because it had absorbed in Precirol ${ }^{\circledR}$ AT05. This becomes a reference that the two sample materials tested are mutually compatible and besides, the absence of new peaks in the FT-IR spectrum pattern also provides information that there is no interaction between Adapalene and Precirol $\AA^{\circledR}$ AT05 so that it does not form new molecular groups (fig. 1).

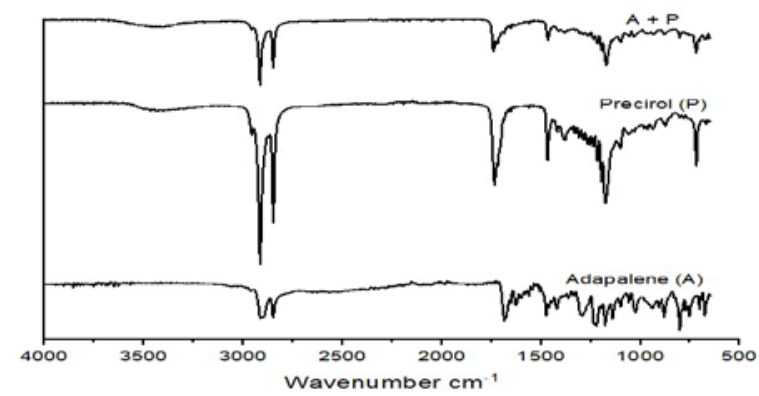

Fig. 1: FTIR absorption spectra of adaplene, precirol, mixture adapalene and precirol

Test X-Ray diffractometry (X-RD) is carried out so that the diffraction data obtained as a result of the collision between the sample material with electromagnetic rays such as X-rays [27]. This test consists of a single adapalene analysis, a single Precirol@ AT05 solid lipid, a mixture of both, and an Apalene NLC using the X-RD Bruker D8 instrument to find out the crystallinity of the material used. Samples were analyzed with a scanning speed of $1^{\circ} / \mathrm{min}$.

XRD test results show that a single Adapalene (plot A) it can be seen that Adapalene has 8 crystalline peaks with 1 high-intensity peak. The more peaks that are formed, the more lattices that can refract $X$ rays. When more rays are transmitted than rays are refracted, the peaks formed will slope so that they have low crystalline properties, conversely the narrower the width of the peaks, the higher the crystalline properties a sample material because the higher the intensity of the light that is refracted.

Based on the diffractogram, it shows that single and has sharp peaks that resemble the phenomenon of grass, whereas a single Precirol ${ }^{\circledR}$ AT05 (plot B) has blunt peaks with low intensity, this shows that the precirol ${ }^{\circledR}$ AT05 dense lipids have the level of crystallinity is lower than that of Adapalene so that when Adapalene is encapsulated by Precirol ${ }^{\circledR}$ AT05 the Plot D displays peaks which indicate that the mixture is amorphous (fig. 2).

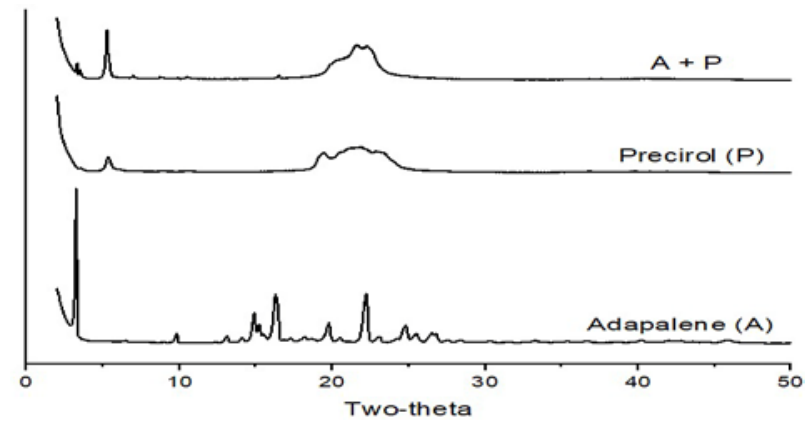

Fig. 2: X-Ray Difraction pattern of adapalene, precirol, mixture adapalene and precirol 
DSC testing is performed to determine the melting point and properties of materials used with endothermic and exothermic phenomena[28]. A total of $10 \mathrm{mg}$ samples (solid lipids Precirol ATO5 ${ }^{\circledR}$, Adapalene, a mixture of solid lipids and Adapalene) were placed in aluminum plates on the DSC instrument. The sample is heated from $20-400{ }^{\circ} \mathrm{C}$ with a heating speed of $10{ }^{\circ} \mathrm{C} /$ minute. Adapalene has crystalline properties, with a high melting point at $326^{\circ} \mathrm{C}$ which indicates the amount of heat energy needed to be able to influence the system inside[29]. Precirol ${ }^{\circledR}$ ATO5 formed a curve in the range of $20.5^{\circ}-83.3^{\circ} \mathrm{C}$ with an endothermic peak at a temperature of $59.6{ }^{\circ} \mathrm{C}$, the mixture between Adapalen and Precirol ${ }^{\circledR}$ ATO5 experienced a narrowing, ie in the range of $19.4^{\circ}$. $77.7^{\circ} \mathrm{C}$ and had a peek at $62.4^{\circ} \mathrm{C}$. This indicates a shift in the melting point that occurs in the mixed sample material after Precirol ${ }^{\circledR}$ AT05 and Adapalene. Mixture thermogram and Adapalene NLC did not form a new peak which states that Adapalene can be completely absorbed on its solid lipid matrix, Precirol $\AA^{\circledR}$ AT05, which is indicated by the loss of the Adapalene peak $\left(59.6^{\circ} \mathrm{C}\right)$ on the mixed thermogram (fig. 3).

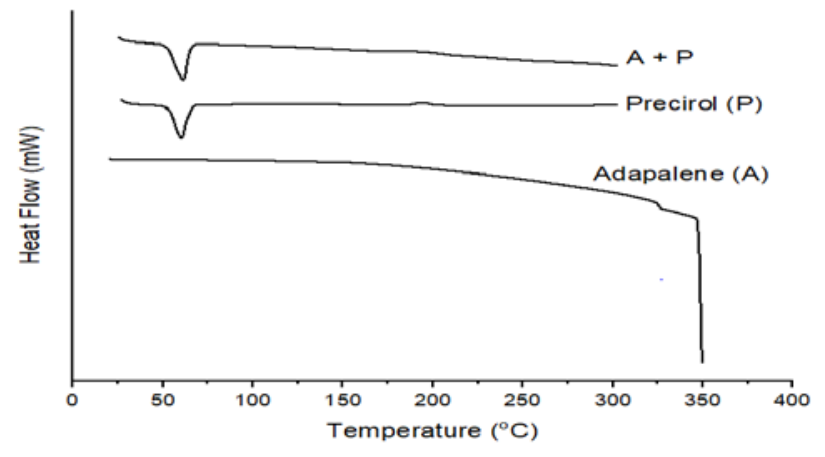

Fig. 3: DSC thermograms of adapalene, precirol, mixture adapalene and precirol

The development of Adapalene NLC formula using Precirol Ato solid lipid with liquid Myritol lipid and using three types of surfactants, namely Plantacare, Ceremophore RH 40 and Tegocare was successfully produced. The parameters used to characterize the adapalene NLC were particle size, index polydispersion, zeta potential, and efficient entrapment. The results showed the measurement of particle size with a range (150-318 nm), index polydispersion showed the homogeneity of the particle size distribution. The data shows
(0.12-0.36) a number below 0.5 , this indicates that NLC formula has a good particle size distribution The zeta potential evaluation provides an overview of the repulsive force between particles that has the potential for particle aggregation, the zeta potential value is close to zero indicating aggregation, causing instability. The data shows that the potential zeta value is more than and result zeta potential showed $(-26)-(-60 \mathrm{mV})$ so the NLC formula has good stability and efficient entrapment testing showed results (84-98\%) (table 1).

Table 1: Formulation and characterization of adapalene loaded NLC

\begin{tabular}{|c|c|c|c|c|c|c|c|c|c|c|}
\hline \multicolumn{7}{|c|}{ Formulation } & \multirow{2}{*}{$\begin{array}{l}\text { Particle size } \\
(\mathrm{nm})\end{array}$} & \multirow[t]{2}{*}{ PdI } & \multirow{2}{*}{$\begin{array}{l}\mathrm{ZP} \\
(\mathrm{mV})\end{array}$} & \multirow{2}{*}{$\begin{array}{l}\text { Entrapment } \\
\text { efficiency (\%) }\end{array}$} \\
\hline Code & $\begin{array}{l}\text { ADA } \\
(\%)\end{array}$ & $\begin{array}{l}\text { PRC } \\
(\%)\end{array}$ & $\begin{array}{l}\text { MYR } \\
(\%)\end{array}$ & $\begin{array}{l}\text { CRE } \\
(\%)\end{array}$ & $\begin{array}{l}\text { PLA } \\
(\%)\end{array}$ & $\begin{array}{l}\text { TGO } \\
(\%)\end{array}$ & & & & \\
\hline 1 & $0.1 \%$ & 2 & 2 & 1 & - & - & $177.46 \pm 7.05$ & $0.12 \pm 0.00$ & $-60.4 \pm 0.21$ & $95.24 \pm 0.07$ \\
\hline 2 & $0.1 \%$ & 3 & 1.75 & 1 & - & - & $175.33 \pm 0.82$ & $0.11 \pm 0.00$ & $-40.7 \pm 12.37$ & $88.80 \pm 0.59$ \\
\hline 3 & $0.1 \%$ & 4 & 1.5 & 1 & - & - & $218.4 \pm 4.57$ & $0.255 \pm 0.00$ & $-50.93 \pm 10.15$ & $93.20 \pm 1.04$ \\
\hline 4 & $0.1 \%$ & 5 & 1.25 & 1 & - & - & $277.6 \pm 13.32$ & $0.31 \pm 0.00$ & $-26.9 \pm 1.88$ & $94.70 \pm 0.00$ \\
\hline 5 & $0.1 \%$ & 6 & 1 & 1 & - & - & $299.8 \pm 2.24$ & $0.26 \pm 0.00$ & $-33.53 \pm 27.26$ & $98.46 \pm 0.00$ \\
\hline 6 & $0.1 \%$ & 2 & 2 & - & 1 & - & $156.03 \pm 6.10$ & $0.26 \pm 0.00$ & $-51.76 \pm 4.12$ & $92.72 \pm 0.21$ \\
\hline 7 & $0.1 \%$ & 3 & 1.75 & - & 1 & - & $173.16 \pm 1.80$ & $0.28 \pm 0.00$ & $-49.3 \pm 9.89$ & $84.93 \pm 0.00$ \\
\hline 8 & $0.1 \%$ & 4 & 1.5 & - & 1 & - & $160.96 \pm 1.71$ & $0.24 \pm 0.00$ & $-53.36 \pm 8.92$ & $94.67 \pm 0.00$ \\
\hline 9 & $0.1 \%$ & 5 & 1.25 & - & 1 & - & $223.66 \pm 2.50$ & $0.29 \pm 0.00$ & $-48.86 \pm 17.84$ & $92.27 \pm 0.42$ \\
\hline 10 & $0.1 \%$ & 6 & 1 & - & 1 & - & $233.66 \pm 2.50$ & $0.49 \pm 0.00$ & $-44.3 \pm 4.18$ & $98.67 \pm 0.00$ \\
\hline 11 & $0.1 \%$ & 2 & 2 & - & - & 1 & $189.76 \pm 14.62$ & $0.29 \pm 0.00$ & $-35.1 \pm 5.66$ & $94.10 \pm 0.58$ \\
\hline 12 & $0.1 \%$ & 3 & 1.75 & - & - & 1 & $198.83 \pm 4.07$ & $0.26 \pm 0.00$ & $-58.8 \pm 1.32$ & $91.91 \pm 0.04$ \\
\hline 13 & $0.1 \%$ & 4 & 1.5 & - & - & 1 & $215.8 \pm 3.37$ & $0.22 \pm 0.00$ & $-59.3 \pm 5.94$ & $92.12 \pm 1.17$ \\
\hline 14 & $0.1 \%$ & 5 & 1.25 & - & - & 1 & $227.13 \pm 1.22$ & $0.28 \pm 0.00$ & $-44.3 \pm 4.18$ & $98.58 \pm 0.00$ \\
\hline 15 & $0.1 \%$ & 6 & 1 & - & - & 1 & $318.73 \pm 3.73$ & $0.36 \pm 0.00$ & $-58.63 \pm 20.65$ & $98.50 \pm 0.00$ \\
\hline
\end{tabular}

ADA: Adapalene, PRC: Precirol, MYR: Myritol, CRE: Cremophore, PLA: Plantacare, TGO: Tegocare, PdI: Polydispersity Index, ZP: Zeta Potential

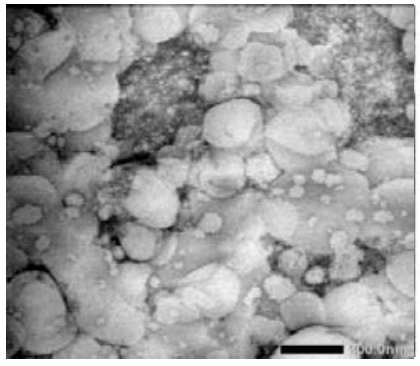

A

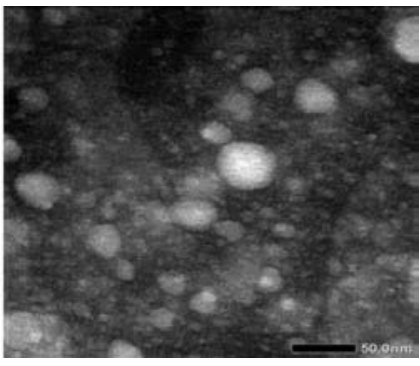

B

Fig. 4: Tranmision electron microscopic photograph imaging of, A (Blank NLC), B (Adap-NLC) 
The results of Microscopic Electronic Transmission showed that the form of NLC with Precirol solid lipids has a spherical shape and has a size below $300 \mathrm{~nm}$ this shows that the NLC produced has a size below $500 \mathrm{~nm}$ and has a correlation in particle size testing and is well distributed. This is related to the results of the NLC characterization of particle size and index polydispersion (fig. 4).

\section{CONCLUSION}

The development of Adapalene NLC formula using Precirol Ato solid lipid with liquid Myritol lipid and using three types of surfactants, namely Plantacare, Ceremophore RH 40 and Tegocare were successfully produced. The parameters used to characterize the adapalene NLC were particle size (90-300) nm, index polydispersion $(<0.5)$, zeta potential- $20 \mathrm{mv}$ up to- $60 \mathrm{mv}$, and efficient entrapment (84-98) \% and morphological evaluation using Transmission electron microscopy (TEM) showed spherical shape.

\section{ACKNOWLEDGEMENT}

The authors are thankful to the Faculty of Pharmacy, Padjadjaran University, for providing the support and their facilities, the Faculty of Pharmacy, Bhakti Kencana University, PT DKSH Indonesia, PT Sagara Purnama Indonesia.

\section{FUNDING}

Nil

\section{AUTHORS CONTRIBUTIONS}

All the authors have contributed equally.

\section{CONFLICT OF INTERESTS}

Declared none

\section{REFERENCES}

1. Zhao J, Piao X, Shi X, Si A, Zhang Y, Feng N. Podophyllotoxinloaded nanostructured lipid carriers for skin targeting: in vitro and in vivo studies. Molecules 2016;21:1549.

2. Lason E, Sikora E, Miastkowska M, Escribano E, Garcia Celma MJ, Solans C, et al. NLCs as a potential carrier system for transdermal delivery of forskolin. Acta Biochim Pol 2018;65:437-42.

3. Rouco H, Diaz Rodriguez P, Remunan Lopez C, Landin M. Recent advances in solid lipid nanoparticles formulation and clinical applications. Nanomaterial for Clinical Application; 2020. p. 213-47.

4. Sathe P, Saka R, Kommineni N, Raza K, Khan W. Dithranolloaded nanostructured lipid carrier-based gel ameliorate psoriasis in imiquimod-induced mice psoriatic plaque model. Drug Dev Ind Pharm 2019;45:826-38.

5. Hanna AP, Ghorab MM, Gad Shadeed. Development of betamethasone dipropionate-loaded nanostructured lipid carriers for topical and transdermal delivery. Anti Inflammatory Anti Allergy Agents Med Chem 2019;18:26-44.

6. Jain A, Garg NK, Jain A, Kesharwani P, Jain AK, Nirbhavane P, et al. A synergistic approach of adapalene-loaded nanostructured lipid carriers, and vitamin C co-administration for treating acne. Drug Dev Ind Pharm 2016;42:897-905.

7. Pariser DM, Thiboutot DM, Clark SD, Jones TM, Liu Y, Graeber M. The efficacy and safety of adapalene gel $0.3 \%$ in the treatment of acne vulgaris: a randomized, multicenter, investigator-blinded, controlled comparison study versus adapalen gel $0.1 \%$ and vehicle. Cutis New York 2005;76:145-51.

8. Rusu A, Tanase C, Pascu GA, Todoran N. Recent advances regarding the therapeutic potential of adapalene. Pharmaceuticals 2020;13:217.

9. Ramezanli T, Michniak Kohn BB. Development and characterization of a topical gel formulation of adapalenetyrospheres and assessment of its clinical efficacy. Mol Pharm 2018;15:3813-22.

10. Shrotriya S, Ranpise N, Satpute P, Vidhate B. Skin targeting of curcumin solid lipid nanoparticles-engrossed topical gel for the treatment of pigmentation and irritant contact dermatitis. Artificial Cells Nanomed Biotechnol 2018;46:1471-82.
11. Ribeiro LNM, Franz Montan M, Alcântara ACS, Breitkreitz MC, Castro SR, Guilherme VA, et al. Hybrid nanofilms as topical anesthetics for pain-free procedures in dentistry. Sci Rep 2020;10:1-11.

12. Ozdemir S, Celik B, Uner M. Properties and therapeutic potential of solid lipid nanoparticles and nanostructured lipid carriers as promising colloidal drug delivery systems. Materials for Biomedical Engineering; 2019. p. 457-505.

13. Yu Y, Feng R, Yu S, Li J, Wang Y, Song Y, et al. Nanostructured lipid carrier-based $\mathrm{pH}$ and temperature dual-responsive hydrogel composed of carboxymethyl chitosan and poloxamer for drug delivery. Int J Biol Macromol 2018;114:462-9.

14. Csanyi E, Suto B, Berko S, Kozma G, Kukovecz A, Budai Szucs M, et al. Development of ibuprofen-loaded nanostructured lipid carrier-based gels: Characterization and investigation of in vitro and in vivo penetration through the skin. Int J Nanomed 2016;11:1201-12.

15. Noh GY, Suh JY, Park SN. Ceramide-based nanostructured lipid carriers for transdermal delivery of isoliquiritigenin: Development, physicochemical characterization, and in vitro skin permeation studies. Korean J Chem Eng 2017;34:400-6.

16. Tofani R, Sumirtapura $\mathrm{Y}$, Darijanto $\mathrm{S}$. Formulation, characterisation, and in vitro skin diffusion of nanostructured lipid carriers for deoxyarbutin compared to a nanoemulsion and conventional cream. Sci Pharm 2016;84:634-45.

17. Makoni PA, Kasongo KW, Walker RB. Short term stability testing of efavirenz-loaded solid lipid nanoparticle (SLN) and nanostructured lipid carrier (NLC) dispersions. Pharmaceutics 2019;11:397.

18. Nagaich U, Gulati N. Nanostructured lipid carriers (NLC) based controlled release topical gel of clobetasol propionate: design and in vivo characterization. Drug Delivery Transl Res 2016;6:289-98.

19. Singh P, Singh M, Kanoujia J, Arya M, Saraf SK, Saraf SA. Process optimization and photostability of silymarin nanostructured lipid carriers: effect on UV-irradiated rat skin and SK-MEL 2 cell line. Drug Delivery Transl Res 2016;6:597-609.

20. Sobczyński J, Bielecka G. Nanostructure lipid carriers. Nanoparticles in Pharmacotherapy; 2019. p. 275-309.

21. Swidan SA, Mansour ZN, Mourad ZA, Elhesaisy NA, Mohamed NA, Bekheet MS, et al. DOE, formulation, and optimization of repaglinide nanostructured lipid carriers. J Appl Pharm Sci 2018;8:8-16.

22. Madan JR, Khobaragade S, Dua K, Awasthi R. Formulation, optimization, and in vitro evaluation of nanostructured lipid carriers for topical delivery of apremilast. Dermatol Ther 2020;33:1-13.

23. Suyanto A, Noor E, Fahma F, Rusli MS, Djatna T. Development of the method of optimized flavor production systems design based on nano-emulsification Kawista (Feronia limonia) Fruit extraction. IOP Conf Ser Earth Environ Sci 2018;102:12-7.

24. Singh Hallan S, Sguizzato M, Pavoni G, Baldisserotto A, Drechsler M, Mariani $\mathrm{P}$, et al. Ellagic acid containing nanostructured lipid carriers for topical application: a preliminary study. Molecules 2020;25:1449.

25. Mendes IT, Ruela ALM, Carvalho FC, Freitas JTJ, Bonfilio R, Pereira GR. Development and characterization of nanostructured lipid carrier-based gels for the transdermal delivery of donepezil. Colloids Surf B 2019;177:274-81.

26. Pawbake GR, Shirolkar SV. Formulation, development and evaluation of nanostructured lipid carrier (NLC) based gel for topical delivery of diacerein. Syst Rev Pharm 2020;11:794-802.

27. Goel S, Sachdeva M, Agarwal V. Nanosuspension technology: recent patents on drug delivery and their characterizations. Recent Pat Drug Delivery Formul 2019;13:91-104.

28. Keivani Nahr F, Ghanbarzadeh B, Hamishehkar H, Samadi Kafil H. Food grade nanostructured lipid carrier for cardamom essential oil: preparation, characterization and antimicrobial activity. J Funct Foods 2018;40:1-8.

29. Nadal JM, Dos Anjos Camargo G, Novatski A, Macenhan WR, Dias DT, Barboza FM, et al. Adapalene-loaded poly( $\varepsilon-$ caprolactone) microparticles: physicochemical characterization and in vitro penetration by photoacoustic spectroscopy. PLoS One 2019;14:e0213625. 